\title{
Question and answer
}

Journal of Medical Genetics, 1980, 17, 476

\section{Question}

Daughters of men with haemophilia have one defective X chromosome; so do the patients' mothers (except in cases due to mutation). So why is it (Blood 1980;55:552-8) that the daughters are found to have less circulating factor VIII coagulant than the mothers? And do other $\mathrm{X}$ linked disorders show a similar pattern?

British Medical Journal 1980, 24 May, p 1275

\section{Answer}

Haemophilia is transmitted as an $\mathrm{X}$ linked disorder and, as a result of this mode of inheritance, all of the daughters of a haemophiliac are carriers and all his sons are normal. When his carrier daughters have children there is a 50:50 chance that their daughters will be carriers and a 50:50 chance that their sons will have haemophilia. Recent work has shown that, on average, the level of circulating factor VIII in carriers is approximately $50 \%$ of that in normal women. This difference has been explained on the basis of $\mathrm{X}$ chromosome inactivation (lyonisation), whereby one in each pair of $\mathrm{X}$ chromosomes in females is rendered inactive in the cell. This process, which is thought to affect the two $\mathrm{X}$ chromosomes randomly, probably also explains why the level of factor VIII in normal women and men is roughly the same despite the fact that women have two $\mathrm{X}$ chromosomes and men only one. In the article referred to above the mean level of factor VIII in음 the blood of obligatory carriers of haemophilia wass found, as expected, to be approximately $50 \%$ of normal. But when those carriers were divided inton those who had derived their haemophilia gene from their father and those who had received it from their. mother, it was observed that the level of factor VIIIin the latter group was significantly higher than that in the former. Providing the groups studied represent random samples of the two categories of carrier the results are of great interest. I know of no similar $\vec{v}$ studies in other $\mathrm{X}$ linked conditions. Christmaso disease (factor IX deficiency) and glucose-6-phos phate dehydrogenase deficiency (G6PD) are botho $\mathrm{X}$ linked disorders and it will be interesting to see if 5 the two types of carriers of those conditions show $\vec{P}$ the same phenomenon as seen in haemophilia. If this is found to be the case one might speculate, ato least in those conditions, that $\mathbf{X}$ chromosome inactivation is not random, the maternal $\mathrm{X}$ chromo- $\frac{\mathrm{O}}{-}$ somes being inactivated more than the paternal ones. $\overrightarrow{0}$

Non-random inactivation of $\mathrm{X}$ chromosomes has been described in humans when one of the $X$ chromo somes is abnormal; also in marsupials there is dence that one $\mathbf{X}$ chromosome is preferentiaffy inactivated, in this case the paternal one.

Without doubt larger numbers of haemophilia气 carriers must be studied to make sure that the differences so far obtained are not the result of non-random selection of carriers. 